\title{
"Finding the Right FIT": Rural Patient Preferences for Fecal Immunochemical Test (FIT) Characteristics
}

\author{
Robyn Pham, BS, Suzanne Cross, MPH, CHW, Bianca Fernandez, BA, \\ Kathryn Corson, PhD, Kristen Dillon, MD, Coco Yackley, BS, \\ and Melinda M. Davis, PhD
}

Purpose: Colorectal cancer (CRC) is the third leading cause of cancer death in the United States, yet 1 in 3 Americans have never been screened for CRC. Annual screening using fecal immunochemical tests (FITs) is often a preferred modality in populations experiencing CRC screening disparities. Although multiple studies evaluate the clinical effectiveness of FITs, few studies assess patient preferences toward kit characteristics. We conducted this community-led study to assess patient preferences for FIT characteristics and to use study findings in concert with clinical effectiveness data to inform regional FIT selection.

Methods: We collaborated with local health system leaders to identify FITs and recruit age eligible (50 to 75 years), English or Spanish speaking community members. Participants completed up to 6 FITs and associated questionnaires and were invited to participate in a follow-up focus group. We used a sequential explanatory mixed-methods design to assess participant preferences and rank FIT kits. First, we used quantitative data from user testing to measure acceptability, ease of completion, and specimen adequacy through a descriptive analysis of 1) fixed response questionnaire items on participant attitudes toward and experiences with FIT kits, and 2) a clinical assessment of adherence to directions regarding collection, packaging, and return of specimens. Second, we analyzed qualitative data from focus groups to refine FIT rankings and gain deeper insight into the pros and cons associated with each tested kit.

Findings: Seventy-six FITs were completed by 18 participants (Range, 3 to 6 kits per participant). Over half $(56 \%, n=10)$ of the participants were Hispanic and $50 \%$ were female $(n=9)$. Thirteen participants attended 1 of 3 focus groups. Participants preferred FITs that were single sample, used a probe and vial for sample collection, and had simple, large-font instructions with colorful pictures. Participants reported challenges using paper to catch samples, had difficulty labeling tests, and emphasized the importance of having care team members provide verbal instructions on test completion and follow-up support for patients with abnormal results. FIT rankings from most to least preferred were OCLight, Hemosure iFOB Test, InSure FIT, QuickVue, OneStep + , and Hemoccult ICT.

Conclusions: FIT characteristics influenced patient's perceptions of test acceptability and feasibility. Health system leaders, payers, and clinicians should select FITs that are both clinically effective and incorporate patient preferred test characteristics. Consideration of patient preferences may facilitate FIT return, especially in populations at higher risk for experiencing CRC screening disparities. (J Am Board Fam Med 2017;30:632-644.)

Keywords: Colorectal Neoplasms, Early Detection of Cancer, Occult Blood, Patient Preference, Treatment Outcome

Colorectal cancer (CRC) is a leading cause of cancer deaths in the United States. ${ }^{1}$ Screening for CRC aids in early detection and treatment of the

This article was externally peer reviewed.

Submitted 7 April 2017; revised ;),14 June 2017; accepted 17 June 2017.

From Oregon Rural Practice-based Research Network, Portland, OR (RP, MMD); Community Health Advocacy disease. ${ }^{2,3}$ However, in 2015 only 63\% of ageeligible adults were up to date with CRC screening, and 1 in 3 adults had never been screened. ${ }^{4,5}$ This

and Research Alliance, Hood River (RP, SC, BF, KC, KD, CY, MMD); Columbia Gorge Health Council, The Dalles (SC, CY); The Next Door, Inc., Hood River (BF); PacificSource Columbia Gorge CCO, Hood River (KD); Depart- 
is far behind the National Colorectal Cancer Roundtable goal to have $80 \%$ of age-eligible adults up to date by $2018 .{ }^{6}$ It also falls behind national screening rates for breast and cervical cancer $(72 \%$ and $81 \%$, respectively). ${ }^{7}$ Further, disparities in CRC screening persist among rural, minority, and low-income groups. ${ }^{5,8,9}$

To improve CRC screening rates and to facilitate early detection and treatment, national experts encourage shared decision making and promoting the message, "the best test is the one that gets done."10,11 The United States Preventive Services Task Force (USPSTF) recommends multiple screening modalities for average-risk adults, including endoscopic (colonoscopy every 10 years; flexible sigmoidoscopy every 5 years) and annual home-based fecal testing options. ${ }^{12}$ Although colonoscopy is commonly used for CRC testing, many resource-challenged communities find that it is not practical for populationlevel screening. ${ }^{13,14}$ Colonoscopy is an expensive test that includes risk of intestinal perforation, requires specially trained medical staff, and has finite capacity, especially in rural areas. ${ }^{15-18}$ Patients may experience barriers to completing colonoscopies related to emotional (eg, fear) and logistic challenges (eg, costs, bowel preparation, transportation, time off work). ${ }^{19-22}$ Some patients, particularly those in populations experiencing low CRC screening rates, prefer home-based fecal testing. ${ }^{23-26}$

Fecal testing is an important component of population-level CRC screening programs, ${ }^{27}$ the success of which depends highly on participation rates. ${ }^{13,28}$ Fecal testing detects hidden (occult) or overt blood in the stool, identifies people who are more likely to have early stage CRC, and directs

ment of Family Medicine \& School of Public Health, Oregon Health \& Science University, Portland (MMD).

Funding: This study was funded in part through a research grant from the Oregon Health and Science University Knight Cancer Institute Community Partnership Program (ID No. CPP.2014.07). Dr. Davis is partially supported by an Agency for Healthcare Research \& Quality patient centered outcomes research (PCOR) K12 award (Award K12 HS022981 01). The Community Health Advocacy and Research Alliance (CHARA) was developed through a series of Pipeline to Proposal Awards from the Patient Centered Outcomes Research Institute (ID 7735932, 7735932-A, $7735932 \mathrm{~B})$. The findings and conclusions in this study are those of the authors and do not necessarily represent the official position of the funders.

Conflict of interest: none declared.

Corresponding author: Melinda M Davis, PhD, 3181 SW Sam Jackson Park Road, Mail Code L222, Oregon Health \& Science University, Portland, OR 97239 (E-mail: davismel@ ohsu.edu.) them to colonoscopy. ${ }^{5}$ More than 130 tests are approved by the US Food and Drug Administration (FDA) for the detection of fecal blood on the Clinical Laboratory Improvement Amendments (CLIA)-waived database as of June 13, 2017 (https://www.accessdata.fda.gov/scripts/cdrh/ cfdocs/cfCLIA/results.cfm). Although guaiac fecal occult blood tests (gFOBT) are cheap and efficacious, they are being replaced by fecal immunochemical tests (FITs) due to superior performance data and higher participation rates. ${ }^{27,29,30}$ Studies suggest that FITs may have greater adherence because they only require 1 or 2 stool samples and they do not require dietary or medication restrictions. ${ }^{31,32}$ However, limited research explores how patients perceive other test characteristics (eg, collection tool, instruction clarity) or allows patients to complete and to compare multiple FITs concurrently.

FITs vary in test effectiveness (eg, sensitivity and specificity) $)^{32,33}$ and other test characteristics (eg, cost, number of samples, collection tool). Although test effectiveness and cost may be primary motivators in FIT selection by clinics and health systems, specific test characteristics may be associated with patient willingness and ability to complete screening as recommended. In 2016, data to inform FIT selection was identified as a priority at Oregon CRC Roundtable. Beyond the number of samples required in a fecal test, we found a paucity of research identifying FIT characteristics associated with completion ${ }^{28}$ and little practical guidance for stakeholders regarding FIT selection. Therefore, we conducted this community-led research study to assess and describe patient preferences for FIT characteristics and to use our novel findings from user testing in concert with evidence on test effectiveness to inform selection of a single FIT that could be utilized by primary care and health system leaders in the study region to improve CRC screening rates.

\section{Methods}

This article utilizes data from Finding the Right FIT, a small-scale community-led study conducted from June 1, 2015 to November 30, 2016 with 3 aims: 1) understand patient preferences for FIT characteristics, 2) assess clinician preferences for CRC screening, and 3) evaluate clinical workflows for fecal testing for CRC. This article reports on 
findings related to patient preferences, which were assessed using a sequential explanatory mixedmethods design. ${ }^{34,35}$ First, we used quantitative data from FIT user testing to measure acceptability, ease of completion, and specimen packaging and adequacy. Second, we gathered qualitative data from focus groups to refine FIT rankings and gain deeper insight into the pros and cons associated with each tested FIT kit.

Study design, data collection, and analysis were driven by community-based team members (SC, $\mathrm{BF}, \mathrm{KC}, \mathrm{CY}, \mathrm{KD}$ ) with the support from academic partners (MD, RP). Our multidisciplinary team had expertise in primary care and community health, health system leadership, popular education and community engagement, and quantitative and qualitative research methodology. This study received approval from the Oregon Health \& Science University Institutional Review Board (IRB No. 11893); we received a full waiver of the HIPAA Authorization of written consent. All team members involved in data collection and analysis completed Human Subjects training.

\section{Regional Context and Study Setting}

This study was led by community and academic partners associated with the Community Health Advocacy and Research Alliance (CHARA; see www.communityresearchalliance.org) and the Columbia Gorge Health Council (CGHC). The CGHC is governed by a board consisting of health care providers, community members, and other stakeholders. ${ }^{36}$ The CGHC oversees a clinical advisory panel, which consists of primary and behavioral clinicians who provide guidance on clinical standards and implement clinical priorities, and a consumer advisory council. The consumer advisory council includes representatives of the community and each county government served by the Coordinated Care Organization (CCO); Medicaid members must constitute a majority of the council's membership. ${ }^{37}$ The CGHC works in partnership with the Columbia Gorge CCO, 1 of 16 accountable care organizations in Oregon that provide coordinated systems of physical and behavioral health care for Medicaid recipients in their region. ${ }^{38,39}$ CCOs were established in 2012 and are accountable to the state through multiple financially-incentivized quality measures, including CRC screening. ${ }^{40,41}$ CRC screening rates across Medicaid members in Oregon's CCOs averaged $46.6 \%$ in
$2015 .^{41}$ The Columbia Gorge CCO's CRC screening rate was $47.3 \%$ in $2015 .{ }^{42}$

The Columbia Gorge CCO includes 2 counties in North-Central Oregon, part of the larger 6-county Columbia Gorge region that spans both Oregon and Washington. The region's 70,000 residents are mostly white, have lower incomes, and are older than the US average. In addition, some counties have up to $31.1 \%$ Latino residents and a significant number of undocumented and uninsured residents. ${ }^{42}$

\section{Materials: FITs}

We worked with local primary care clinics and the clinical advisory panel to identify 6 FIT kits for inclusion, see Table 1. Five FITs (OneStep+, InSure FIT, QuickVue, Hemosure iFOB Test, Hemoccult ICT) were used by primary care clinics within the Columbia Gorge CCO. One FIT (OCLight) was used widely by other CCOs in Oregon and being considered for use by a clinic in the study region. These FITs varied in terms of collection tools and methods, number of required samples, packaging, instructions, and clinical characteristics (see Table 1). Although laboratory processing of completed FITs was outside the scope of our current study, all 6 FITs were CLIA waived and could be manually processed at the point of care. We could not locate published data on clinical performance for 2 of the tests, QuickVue and OneStep+. Photographs of each FIT kit appear in Appendix 1.

\section{Participants and Recruitment}

We engaged local health and social service providers and a bilingual community health worker (BF) to assist with participant recruitment. We distributed English and Spanish recruitment fliers to consumer advisory council and clinical advisory panel members of the CCO and posted them in public health departments, primary care clinics, and local businesses. We also produced a study public service announcement that was broadcasted on a local Spanish-language radio station.

We sought to enroll up to 30 participants in user testing, with the intent to recruit at least $50 \%$ Spanish-speaking adults. Eligible participants were 1) residents in the Columbia Gorge region, 2) English or Spanish speaking, 3) uninsured or receiving government insurance coverage, and 4) age eligible for CRC screening (ie, 50 to 75 years). We originally targeted Medicaid patients in the CCO re- 


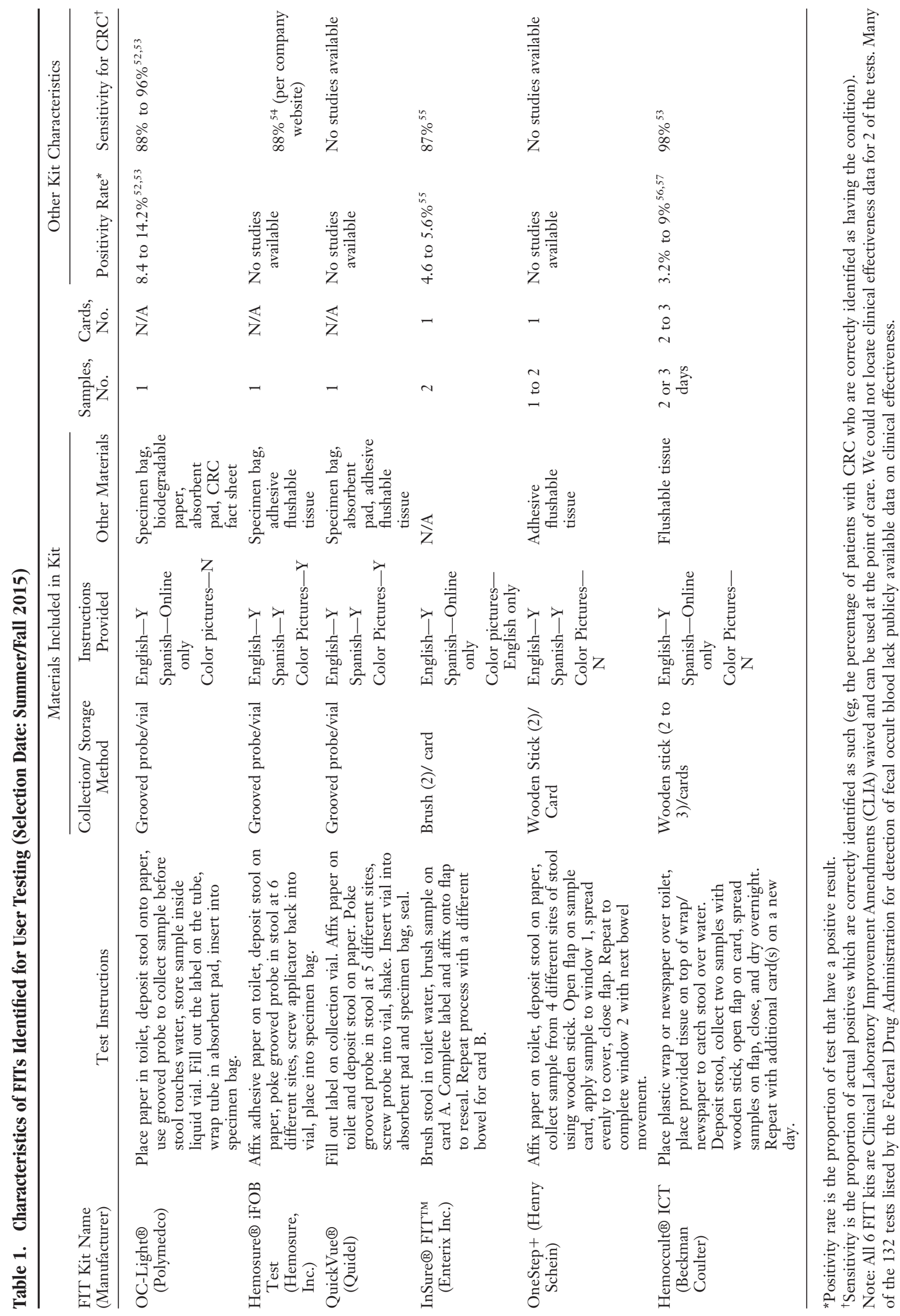


gion, but we expanded eligibility to include participants in the broader Columbia Gorge region to increase the final sample size. We conducted an intake call to assess interest and eligibility. Eligible participants were invited to participate in user testing and a focus group. Participants received a \$25 gift card for completing up to 3 FIT kits, a $\$ 50$ gift card for completing 6 kits, and an additional \$50 gift card for attending a focus group. Participants could elect to have 1 of the completed FITs returned to their primary care clinic for clinical processing and followup. Participants had to return at least 1 completed questionnaire and a FIT kit to be included in the final analysis.

\section{Data Collection and Analysis}

A bilingual community health worker (BF) enrolled participants, distributed FIT kits and questionnaires in a participant's preferred language (English or Spanish), and instructed them to complete the kits according to manufacturer instructions. Participants were instructed to place all completed kits and questionnaires in a single preaddressed mailer for return to study staff.

\section{Questionnaires}

For each FIT, participants were asked to complete a 20-item questionnaire that assessed ease of completion (eg, unpacking, mailing), instruction clarity, attitudes toward the process, and time to complete (see example in Appendix 2). Items on the questionnaire were gathered from existing instruments ${ }^{43,44}$ and revised using partner feedback to facilitate readability (Flesch-Kincaid Grade Level: 4.4). The questionnaire was reviewed by local partners for cultural literacy and translated into Spanish by a certified translator at a regional partner organization. Items employed Likert-style and openended response options. For the 13 fixed-response items, we calculated the percentage of participants who endorsed positively worded items (ie, "Agree" or "Strongly Agree") and who did not endorse negatively directed items (ie, "Disagree" or "Strongly Disagree"). For each item, we then identified the highest and lowest performing kit(s) based on these percentages. Due to the small sample sizes, we provide descriptive statistics only. A sensitivity analysis found no significant diffidences in the probability of a favorable survey response for those completing 3 versus 6 kits. Open-ended response-options were categorized as "pro" or "con" and tabulated. Analyses were conducted using IBM SPSS Statistics 22.0.

\section{Focus Groups}

Three focus groups (1 English and 2 Spanish language) were facilitated by community health workers using a semistructured interview guide (see Appendix 3). Additional project staff attended focus groups to audio record each session, collect detailed field notes, and record FIT prioritization using flip charts. Focus groups lasted 90 minutes on average. The project manager (SC) and the community health worker (BF) used field notes and flip chart lists to prioritized FITs and identify characteristics that facilitated or impeded sample collection. Three team members (RP, MD, KD) conducted an inductive qualitative descriptive analysis to identify patient preferred FIT characteristics. $^{45,46}$ This included an independent review of field notes followed by group meetings to review codes, reconcile discrepancies, and to identify and finalize emergent themes.

\section{Specimen Adequacy Analysis}

Participants could elect to have 1 completed kit returned to their primary care clinic for laboratory processing. All other returned FITs were included in a specimen adequacy analysis completed by a physician (KD) to assess 3 main attributes: 1 ) adequacy of the sample provided, 2) labeling of the specimen kit, and 3) packaging of kit for shipping. FITs that were returned to participants' primary care clinic for routine clinical care were excluded from the specimen analysis. Criteria for an adequate specimen collection were not included in the manufacturer instructions. Therefore, a descriptive specimen evaluation rubric was developed through an initial examination of kits returned by 5 participants, expert consultation, and input from the study team (Appendix 4); all kits were then evaluated in a single session. Specimens were rated for adequacy using a visual assessment of coloration in vial tests (clear, tan, or brown) or percentage coverage of a card's test area (more than $50 \%$ ). In addition, we assessed whether participants attempted to label vials or cards as outlined in the instructions, and if different collection dates were noted for multi-day kits. Finally, we evaluated adherence to manufacturer instructions for repackaging completed kits. 
Table 2. Demographic Characteristics of Participants Engaged in FIT Testing and Focus Groups

\begin{tabular}{lcc}
\hline Characteristics & $\begin{array}{r}\text { Completed FIT Kits and Questionnaires } \\
(\mathrm{N}=18)\end{array}$ & $\begin{array}{c}\text { Participated in Focus Group } \\
(\mathrm{N}=13)\end{array}$ \\
\hline Female & $9(50)$ & $8(62)$ \\
Age, mean (SD) & $55.6(4.3)$ & $55.5(7.4)$ \\
Hispanic & $10(55.6)$ & $7(53.8)$ \\
Primary language & & $7(53.8)$ \\
English & $9(50.0)$ & $6(46.2)$ \\
Spanish & $9(50.0)$ & $6(46.2)$ \\
Insurance & & $0(0)$ \\
Medicaid & $9(50.0)$ & $5(38.4)$ \\
Medicare & $2(11.1)$ & $2(15.4)$ \\
Uninsured & $3(16.7)$ & $0(0)$ \\
Private & $3(16.7)$ & $9(69.2)$ \\
Unknown & $1(5.5)$ & $2(15.4)$ \\
County of residence & & $1(7.7)$ \\
Wasco & $10(55.6)$ & $1(7.7)$ \\
Hood river & $5(27.8)$ & $1(7.7)^{\dagger}$ \\
Multnomah & $2(11.0)$ & $1(5.6)$ \\
Klickitat & $5(29)^{*}$ & \\
FIT or gFOBT in prior 3 years & & \\
\hline
\end{tabular}

${ }^{*} \mathrm{~N}=17$.

${ }^{\dagger} \mathrm{N}=12$.

\section{FIT Kit Final Ranking}

Two members of the study team (SC, KD) reviewed findings from the questionnaires, specimen evaluation, and focus groups to create a preliminary list of preferred tests and test characteristics. This list was reviewed by the full study team and refined using themes from the focus groups. Differences in FIT rankings were resolved through consensus.

\section{Results}

A total of 76 FIT kits and 76 questionnaires were completed by 18 participants (mean, 4 FITs per participant; range, 3 to 6 FITs). As summarized in Table 2, mean participant age was 56 years (range, 50 to 66 years), $50 \%(\mathrm{n}=9)$ were female and $56 \%$ $(\mathrm{n}=10)$ self-identified as Hispanic. Over half of the participants received government subsidized health insurance including Medicaid or Medicare (61\%); 3 participants (17\%) were uninsured. Thirteen individuals attended 1 of 3 focus groups: 10 who completed FIT kits and questionnaires, 3 who had not ( 2 were 49 years old, 1 was 78 years old). Seven $(54 \%)$ focus group participants were Hispanic.

\section{Questionnaires}

Participant agreement or disagreement with key statements about each FIT kit are summarized in Table 3. Participants reported the most challenges with the Hemoccult ICT kit, which employs a wooden stick for sample collection and requires multiple samples that are dried between collection days. The OneStep + kit also employs a wooden stick, but was viewed as easier than completing the Hemoccult ICT. Participants generally responded positively to the other kits. Participants generally agreed with the statement that collecting the sample was quick (range, $60 \%$ to $92 \%$ ) and reported that they felt confident that they completed the kit correctly (range, 64\% to $86 \%)$. However, the majority of participants viewed kit completion as disgusting (range, 18\% to $55 \%$ disagreed).

Overall, participants rated FITs that used probes for sample collection the highest. All respondents reported that the Hemosure iFOB Test and OCLight probes were easy to use and that they had minimal problems with sample collection. Over $90 \%$ of participants found the InSure brush easy to use for sample collection. Although QuickVue and Hemosure iFOB has similar characteristics to OC- 


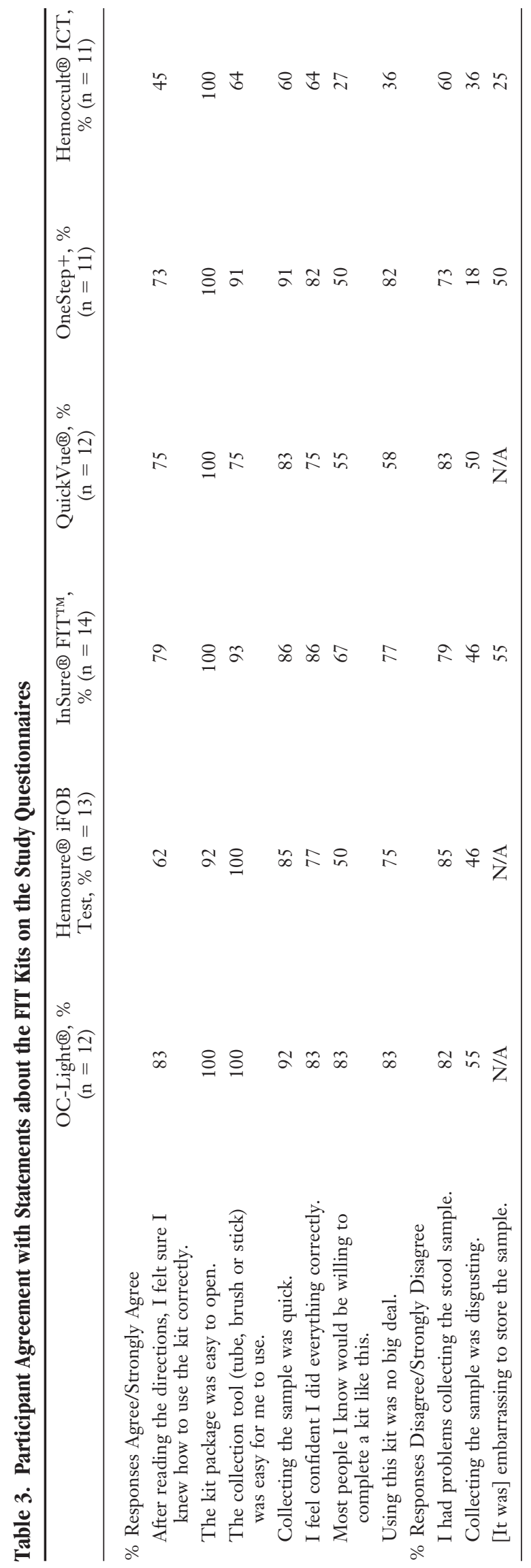

Light (ie, probe, 1 sampling day), participants rated OC-Light more favorably.

\section{Focus Groups}

Four themes emerged from focus groups pertaining to preferences for FIT characteristics and CRC screening. First, in contract to colonoscopy, participants liked that fecal tests could be completed at home, were convenient, generally easy to use, and required no preparation in advance. Second, participants preferred tests that required " 1 trip to the bathroom" to complete and provided a grooved probe for collecting the sample. In contrast, they disliked collection sticks, multi-sample tests, and cards that required drying samples overnight. However, focus group participants raised questions about how much stool was needed to satisfy a sample, why some kits required 6 pokes while others only 1 , and expressed concerns about the effectiveness of using the provided paper to catch the stool sample. Because participants experienced problems with the paper provided to hold the stool sample, they recommended using a pie tin or collection hats, such as those provided in hospitals. In addition, some participants wondered whether tests with more cards/samples were better able to detect CRC than single-sample tests. Third, participants preferred instructions printed in large font with colorful pictures and were appropriately translated. Specifically, Spanish speakers requested instructions written for Spanish readers instead of relying on automatic translation. In addition, focus-group participants noted that having a care team member or community health worker review the FIT with them was helpful in understanding how to complete the test and recommended creating instructional videos that could accompany the tests or available on YouTube. Finally, focus groups identified barriers to CRC screening irrespective of modality such as cost, fear, and cultural sensitivities. Participants stressed the importance of providing follow-up care and navigation support for colonoscopy scheduling to patients with abnormal FIT results.

\section{Specimen Adequacy Analysis}

Table 4 summarizes findings from the specimen evaluation of 66 returned FIT kits $(86 \%)$ in relation to sample adequacy, labeling, and packaging; the remaining 11 FITs were sent to participants' primary care clinics for processing. Nearly all, 
Table 4. Descriptive Findings from the FIT Kit Specimen Adequacy Analysis $(\mathrm{N}=66)$

\begin{tabular}{|c|c|c|c|c|c|c|}
\hline & $\begin{array}{c}\text { OC-Light }{ }^{\circledR} \\
(\mathrm{n}=12)\end{array}$ & $\begin{array}{l}\text { Hemosure }{ }^{\circledR} \text { iFOB } \\
\text { Test }(n=13)\end{array}$ & $\begin{array}{l}\text { InSure }{ }^{\circledR} \text { FITT }^{\mathrm{TM}} \\
\quad(\mathrm{n}=7)\end{array}$ & $\begin{array}{l}\text { QuickVue® } \\
(\mathrm{n}=11)\end{array}$ & $\begin{array}{c}\text { OneStep }+ \\
(\mathrm{n}=12)\end{array}$ & $\begin{array}{c}\text { Hemoccult }{ }^{\circledR} \mathrm{ICT} \\
(\mathrm{n}=11)\end{array}$ \\
\hline Packaged correctly & $7(58)$ & $8(62)$ & $7(100)$ & $8(73)$ & $12(100)$ & $10(91)$ \\
\hline In mailer $(\mathrm{Y})$ & $11(92)$ & $11(85)$ & $7(100)$ & $10(91)$ & $12(100)$ & $10(91)$ \\
\hline In bio bag $(\mathrm{Y})$ & $8(67)$ & $11(85)$ & N/A & $11(100)$ & N/A & N/A \\
\hline With pad (C) & $7(58)$ & $8(62)$ & N/A & $9(82)$ & N/A & N/A \\
\hline Labeled correctly & $8(67)$ & $5(38)$ & $6(86)$ & $5(45)$ & $8(67)$ & $7(64)$ \\
\hline Label (Y) & $7(58)$ & $5(38)$ & $5(71)$ & $5(45)$ & $7(58)$ & $7(64)$ \\
\hline Different days $(\mathrm{Y})$ & N/A & N/A & $4(57)$ & N/A & $4(33)$ & $5(45)$ \\
\hline Collection date $(\mathrm{Y})$ & $8(67)$ & $5(38)$ & $6(86)$ & $4(36)$ & $7(58)$ & $7(64)$ \\
\hline Sampled correctly & $10(83)$ & $12(92)$ & $6(86)$ & $11(100)$ & $11(92)$ & $7(64)$ \\
\hline Color of liquid (T/B) & $10(83)$ & $12(92)$ & N/A & $11(100)$ & N/A & N/A \\
\hline Returned all cards & N/A & N/A & $7(100)^{*}$ & N/A & $12(100)^{*}$ & $9(82)^{\dagger}$ \\
\hline Sample on all cards & N/A & N/A & $7(100)$ & N/A & $11(92)$ & $8(73)^{\dagger}$ \\
\hline Specimen appearance & N/A & N/A & $7(100)$ & N/A & $12(100)$ & $10(91)$ \\
\hline Coverage $(>50 \%)$ & N/A & N/A & $6(86)$ & N/A & $11(92)$ & $7(64)$ \\
\hline Closed & N/A & N/A & $7(100)$ & N/A & $12(100)$ & $10(91)$ \\
\hline
\end{tabular}

B, brown; C, correct; T, tan; Y, yes.

*1 card total.

${ }^{\dagger} 3$ cards total.

92\% (33/36), vial-based kits had an adequate specimen (ie, liquid in the vial was tan or brown in color) whereas $80 \%(24 / 30)$ of card-based kits had an adequate sample (ie, specimen covered $\geq$ $50 \%$ of the test area). Many multi-sample cards, especially kits that required 2 samples on 1 card, appeared to have been completed with a single sample.

When participants attempted to write on vials that had preattached labels, their handwriting was often illegible. However, only 38\% (5/13) of Hemosure iFOB Test kits were labeled compared with $86 \%(6 / 7)$ of InSure FIT kits. Kit packaging also varied widely. Overall, 64\% (23/36) of vial-based tests were packaged correctly. Specifically, $83 \%$ (30/36) of the vial-based tests were properly returned in the biohazard bag, but only 55\% (24/36) were wrapped in the absorbent pad. Packaging errors on vial tests included placing the vial directly in the mailer without enclosing in the biohazard bag and returning the vial without the absorbent pad included. Comparatively, 97\% (29/30) of card based tests were packed according to manufacturer instructions with secured card flaps over the sample site with stickers. However, 2 of the mailing envelopes included waste materials from the kit, making them too heavy for mailing with the recommended postage.

\section{Final FIT Ranking}

As summarized in Table 5, the top 2 tests (OCLight and Hemosure iFOB Test) utilized a probe and required a single sample. The third FIT (InSure FIT) required a brush and 2 days of sampling, yet ranked highly on all assessments in part due to a colorful and clear instruction sheet.

\section{Discussion}

Participants in our study clearly preferred FITs that use a probe and vial for collection, had simple instructions that include large font text and colorful pictures, and require only 1 sample. Participants had difficulty providing accurate and legible labeling on samples, and multi-specimen tests often seemed to have been completed with a single sample. Final FIT rankings from most to least preferred were OC-Light, Hemosure iFOB Test, InSure FIT, QuickVue, OneStep+, and Hemoccult ICT. In addition, participants provided suggestions for kit improvement, described the benefit of having care team members provide verbal instructions for FIT completion, and stressed the importance of providing follow-up care and navigation support for patients with abnormal results. Attending to patient preferred FIT characteristics may facilitate patient return, clinical processing, and thus im- 
Table 5. FIT Kit Rankings from Most to Least Preferred by Questionnaire and Focus Group Data A. Combined Rankings for FIT Kit User Testing Data Sets

\begin{tabular}{|c|c|c|c|c|}
\hline \multirow[b]{2}{*}{ FIT Name } & \multicolumn{3}{|c|}{ Data Source } & \multirow[b]{2}{*}{ Overall } \\
\hline & $\begin{array}{l}\text { Questionnaire } \\
\quad(\mathrm{n}=79)\end{array}$ & $\begin{array}{l}\text { English Focus Group } \\
\qquad(\mathrm{n}=6)\end{array}$ & $\begin{array}{l}\text { Spanish Focus Group } \\
\qquad(\mathrm{n}=8)\end{array}$ & \\
\hline OC-Light ${ }^{\circledR}$ & 1 & 1 & $2 / 3^{*}$ & 1 \\
\hline Hemosure ${ }^{\circledR}$ iFOB Test & $2 / 3^{*}$ & 3 & 1 & 2 \\
\hline InSure ${ }^{\circledR}$ FIT $^{\mathrm{TM}}$ & $2 / 3^{*}$ & 2 & $2 / 3^{*}$ & 3 \\
\hline QuickVue® & 4 & 4 & 4 & 4 \\
\hline OneStep+ & 5 & 5 & 5 & 5 \\
\hline Hemoccult@ ICT & 6 & 6 & 6 & 6 \\
\hline
\end{tabular}

*2/3 signifies a tie for second place.

\section{B. Test Characteristics for Overall FIT Kit Ranking}

\begin{tabular}{|c|c|c|c|c|c|c|c|c|c|c|c|}
\hline \multirow[b]{2}{*}{ Kit Ranking } & \multicolumn{3}{|c|}{ Collection Tool } & \multicolumn{2}{|c|}{ Instructions } & \multicolumn{3}{|c|}{$\begin{array}{l}\text { No. Sampling } \\
\text { Days }\end{array}$} & \multicolumn{3}{|c|}{ No. Cards } \\
\hline & Probe & Stick & Brush & $\begin{array}{l}\text { Colored } \\
\text { Pictures }\end{array}$ & $\begin{array}{c}\text { Large } \\
\text { Font }\end{array}$ & 1 & 2 & 3 & 1 & 2 & 3 \\
\hline 1. OC-Light $\circledast$ & $\mathrm{X}$ & & & & $\mathrm{X}$ & $\mathrm{X}$ & & & & & \\
\hline 2. Hemosure ${ }^{\circledR}$ iFOB Test & $\mathrm{X}$ & & & $\mathrm{X}$ & $\mathrm{X}$ & $\mathrm{X}$ & & & & & \\
\hline 3. InSure ${ }^{\circledR}$ FIT $^{\mathrm{TM}}$ & & & $\mathrm{X}$ & $\mathrm{X}$ & & & $\mathrm{X}$ & & $\mathrm{X}$ & & \\
\hline 4. QuickVue® & $\mathrm{X}$ & & & $\mathrm{X}$ & & $\mathrm{X}$ & & & & & \\
\hline 5. OneStep+ & & $\mathrm{X}$ & & & $\mathrm{X}$ & & $\mathrm{X}$ & & $\mathrm{X}$ & & \\
\hline 6. Hemoccult $\circledast \mathrm{ICT}$ & & $\mathrm{X}$ & & & & & $\mathrm{X}$ & $\mathrm{X}$ & & $\mathrm{X}$ & $\mathrm{X}$ \\
\hline
\end{tabular}

prove CRC screening rates and ultimately reduce cancer morbidity and mortality.

Current guidelines and national recommendations emphasize helping patients use the CRC screening modality that best suits their preferences. ${ }^{10,11}$ Our study evaluated FITs, which before fall 2016 were 1 of 3 screening modalities recommended by the USPSTF. ${ }^{12,47}$ In the United States and internationally, FITs are replacing older gFOBT options as the standard of care for homebased fecal testing for CRC due to superior performance data and higher participation rates. ${ }^{27,29,30}$ Currently, 132 different tests are cleared for use in the United States by the FDA for the "detection of blood" in the stool. We assessed 6 FITs that were actively being used by primary care clinics within 1 region. However, 2 of the selected FITs did not include published data on clinical effectiveness. A 2013 study by Daly and colleagues ${ }^{32}$ found that many FOBT/FIT products listed on the FDA website lacked publicly available proficiency testing information to help health-care professionals make informed decisions regarding test selection. An important consideration for future research is how to generate publicly available data on FIT effective- ness, and how best to support the adoption and use of FITs that are clinically effective and preferred by patients in practice.

Test effectiveness is a critical factor to consider when selecting a FIT kit. However, other physical test characteristics may determine whether patients complete these tests and if they do so correctly. Understanding how patients view the characteristics of FITs currently available on the market can inform product refinement and may facilitate completion. Previous research identified preferences for certain FITs, such as those that only require a single sample. ${ }^{31,48}$ Other studies have assessed patient perceptions of FIT/FOBTs and reason for completion. ${ }^{43,48-50}$ For example, Gordon and colleagues ${ }^{49}$ identified nonusers discomfort in completing the kit and user suggestions to add disposable gloves, extra paper, and wider-mouth collection vials. However, no studies that we are aware of allow patients complete multiple FITs such that they can compare and contrast between them. Our study addresses key gaps in the research by identifying multiple characteristics that patients perceive make specific FITs easier to complete. Although initially our study set out to recommend a single FIT kit, we found that 
patients preferred test characteristics shared by more than 1 kit.

There are a few notable limitations in the present study. First, we tested 6 FITs that were actively used in the region and varied in their clinical effectiveness, 2 of which did not have publicly available data on clinical effectiveness. Health-system leaders should consider both clinical and physical test characteristics when selecting a FIT for local or regional use. In addition, there may be other FIT characteristics that merit evaluation. Second, we had difficulty recruiting users in our original target population. In response, we expanded our geographic range, included individuals beyond those covered by Medicaid, extended the recruitment timeframe, and implemented protocols to allow participants to return 1 test to their primary care practice for laboratory testing. Attending to these factors as well as asking patients to complete fewer FITs may facilitate recruitment in future studies. Third, our study was a small-scale communitybased study primarily designed to inform FIT selection in 1 rural region. Although 76 FITs were completed, they were returned by 18 participants who all identified as either white or Hispanic/Latino. Future studies with a larger, more diverse participant sample could evaluate how FIT preferences differ by participant characteristics (eg, low vs higher socioeconomic status) and may reveal different preferences across racial/ethnic subgroups and regions. Lastly, although we allowed participants to send 1 kit for laboratory analysis, our assessment of sample adequacy used a qualitative rubric designed through expert consultation. Given that we assessed color and/or card coverage and instructed participants not to label tests with their names, actual laboratory processing may have resulted in different outcomes for sample completion.

Despite these limitations, we observed variation in participants' ability to complete and their perceptions of different FITs. Our findings add to the body of knowledge on patient perceptions of FIT acceptability and feasibility of use. Results-when used in concert with data on clinical effectivenesscan inform primary care clinicians, health-system leaders, and payers who seek to increase CRC screening through home-based fecal testing. In addition, findings provide important feedback for manufacturers who can improve kit characteristics (eg, collection method) and to refine the associated instructions to address patient concerns with com- pleting the test (ie, what if sample gets wet). Although some systems and research teams have created pictographs or wordless instructions for lowliteracy adults, ${ }^{51}$ changes by the manufacturer could support widespread distribution and uptake in low as well as high resourced settings. Finally, our results can advise the design of future studies that assess additional FIT kits in larger samples that extend beyond rural English and Spanish speakers and single geographic regions. These studies can offer more sophisticated analyses measuring adequacy of returned FITs and tease apart the association between FIT kit characteristics (eg, number of samples, collection method, instructions) on patient adherence in clinical practice.

\section{Conclusion}

Test characteristics influenced patient's perceptions of FIT acceptability and feasibility of use. Study participants preferred FITs that required only 1 sample, used a probe and vial to collect the sample, and had descriptive instructions with large font and colored pictures. Participants reported difficulty using paper to catch samples, had difficulty labeling tests, and emphasized the importance of having care team members provide instruction on test completion and offer follow-up support for patients with an abnormal result. Findings can be used by manufacturers to improve test characteristics and by researchers to inform larger-scale studies and intervention trials. When considered in concert with information on FIT effectiveness, clinics and health systems can use our results to inform test selection.

We thank our study participants and the various community partners who supported study recruitment. The Columbia Gorge Health Council served as the fiscal agent, provided time for staff participation, and supported engagement of the Columbia Gorge Coordinated Care Organization's Community Advisory Council and Clinical Advisory Panel. The Community Health Advocacy and Research Alliance (CHARA) provided training and infrastructure that enabled the current study. Gloria Coronado, $\mathrm{PhD}$ helped team members identify and procure FITs. Staff from Nuestra Comunidad Sana at The Next Door, Inc. created community flyers and translated Spanish surveys. FITs used in this study were donated by the manufactures: Beckman Coulter, Polymedco, Henry Schein, Hemosure, Enterix (also known as Clinical Genomics USA), and Quidel. We appreciate the assistance of Eliana Sullivan with manuscript revisions and Katrina Ramsey with quantitative analysis.

To see this article online, please go to: http://jabfm.org/content/ 30/5/632.full. 


\section{References}

1. Colorectal Cancer Facts \& Figures 2014-2016. Atlanta, GA: American Cancer Society; 2014.

2. Zauber AG, Lansdorp-Vogelaar I, Knudsen AB, et al. Evaluating test strategies for colorectal cancer screening: A decision analysis for the U.S. Preventive Services Task Force. Ann Intern Med 2008;149: 659-69.

3. Whitlock EP, Lin JS, Liles E, et al. Screening for colorectal cancer: A targeted, updated systematic review for the U.S. preventive services task force. Ann Intern Med 2008;149:638-58.

4. Morbidity, and Mortality Weekly Report (MMWR). Vital signs: Colorectal cancer screening test useUnited States, 2012. MMWR Morb Mortal Wkly Rep 2013;62:881-8.

5. Society AC. Colorectal Cancer Facts \& Figures 2017-2019. Atlanta, GA: American Cancer Society; 2017.

6. $80 \%$ by 2018. 2016. Available from: http://nccrt.org/ tools/80-percent-by-2018. Accessed on January 23, 2017.

7. Sabatino SA, White MC, Thompson TD, et al. Cancer screening test use-United States, 2013. MMWR Morb Mortal Wkly Rep 2015;64:464-8.

8. Cole AM, Jackson JE, Doescher M. Urban-rural disparities in colorectal cancer screening: Cross-sectional analysis of 1998-2005 data from the Centers for Disease Control's Behavioral Risk Factor Surveillance Study. Cancer Med 2012;1:350-6.

9. Davis MM, Pham R, et al. Geographic and popluation-level disparities in colorectal cancer screening: A multilevel analysis if medicaid and commercial claims data. Prev Med 2017;101:44-52.

10. Gupta S, Sussman DA, Doubeni CA, et al. Challenges and possible solutions to colorectal cancer screening for the underserved. J Natl Cancer Inst 2014;106(4):dju032.

11. Lieberman D, Ladabaum U, Cruz-Correa M, et al. Screening for colorectal cancer and evolving issues for physicians and patients: A review. JAMA 2016; 316:2135-45.

12. United States Preventive Services Task Force (USPSTF). Final Update Summary: Colorectal Cancer: Screening. 2016.

13. Honein-AbouHaidar GN, Kastner M, Vuong V, et al. Benefits and barriers to participation in colorectal cancer screening: a protocol for a systematic review and synthesis of qualitative studies. BMJ Open 2014; 4(2):e004508.

14. Mackie A. Moving from guaiac faecal occult blood test $(\mathrm{gFOBT})$ to a faecal immunochemical test for haemoglobin (FIT) in the bowel screening programme: A consultation. 2015.

15. Levin B, Lieberman DA, McFarland B, et al. Screening and surveillance for the early detection of colorectal cancer and adenomatous polyps, 2008: A joint guideline from the American Cancer Society, the US Multi-Society Task Force on Colorectal Cancer, and the American College of Radiology. CA Cancer J Clin 2008;58(3):130-60.

16. Levin TR, Zhao W, Conell C, et al. Complications of colonoscopy in an integrated health care delivery system. Ann Intern Med 2006;145:880-6.

17. Hoffman RM, Espey D, Rhyne RL. A public-health perspective on screening colonoscopy. Expert Rev Anticancer Ther 2011;11:561-9.

18. Panteris V, Haringsma J, Kuipers EJ. Colonoscopy perforation rate, mechanisms and outcome: From diagnostic to therapeutic colonoscopy. Endoscopy 2009;41:941-51.

19. Schoenberg NE, Eddens K, Jonas A, et al. Colorectal cancer prevention: Perspectives of key players from social networks in a low-income rural US region. Int J Qual Stud Health Well-being 2016;11(1):30396.

20. Bowyer HL, Vart G, Kralj-Hans I, et al. Patient attitudes towards faecal immunochemical testing for haemoglobin as an alternative to colonoscopic surveillance of groups at increased risk of colorectal cancer. J Med Screen 2013;20(3):149-56.

21. Ruffin MT 4th, Creswell JW, Jimbo M, Fetters MD. Factors influencing choices for colorectal cancer screening among previously unscreened African and Caucasian Americans: Findings from a triangulation mixed methods investigation. J Community Health 2009;34(2):79-89.

22. Green BB, Coronado GD, Devoe JE, et al. Navigating the murky waters of colorectal cancer screening and health reform. Am J Public Health 2014;104: 982-6.

23. Inadomi JM, Vijan S, et al. Adherence to colorectal cancer screening: A randomized clinical trial of competing strategies. Arch Intern Med 2012;172: 575-82.

24. Shokar NK, Carlson CA, Weller SC. Informed decision making changes test preferences for colorectal cancer screening in a diverse population. Ann Fam Med 2010;8:141-50.

25. DeBourcy A, Lichtenberger S, Felton S, et al. Community-based preferences for stool cards versus colonoscopy in colorectal cancer screening. J Gen Intern Med 2008;23:169-74.

26. Gupta S, Halm EA, Rockey DC, et al. Comparative effectiveness of fecal immunochemical test outreach, colonoscopy outreach, and usual care for boosting colorectal cancer screening among the underserved: A randomized clinical trial. JAMA Intern Med 2013; 173:1725-32.

27. Allison JE, Fraser CG, Halloran SP, et al. Population screening for colorectal cancer means getting FIT: The past, present, and future of colorectal cancer screening using the fecal immunochemical test for hemoglobin (FIT). Gut Liver 2014;8:117-30.

28. Vart G, Banzi R, Minozzi S. Comparing participation rates between immunochemical and guaiac fae- 
cal occult blood tests: A systematic review and metaanalysis. Prev Med 2012;55:87-92.

29. Tinmouth J, Lansdorp-Vogelaar I, Allison JE. Faecal immunochemical tests versus guaiac faecal occult blood tests: What clinicians and colorectal cancer screening programme organisers need to know. Gut 2015;64:1327-37.

30. World Endoscopy Organization. FIT for Screening. 2017. Available from: http://www.worldendo.org/ about-us/committees/colorectal-cancer-screening/ ccs-testpage2-level4/fit-for-screening. Accessed Jan 31, 2017.

31. Chubak J, Bogart A, Fuller S, et al. Uptake and positive predictive value of fecal occult blood tests: A randomized controlled trial. Prev Med 2013;57: 671-8.

32. Daly JM, Bay CP, Levy BT. Evaluation of fecal immunochemical tests for colorectal cancer screening. J Prim Care Community Health 2013;4:245-50.

33. Lee JK, Liles EG, Bent S, et al. Accuracy of fecal immunochemical tests for colorectal cancer: Systematic review and meta-analysis. Ann Intern Med 2014; 160:171.

34. Creswell JW, Plano Clark VL. Designing and Conducting Mixed Methods Research. 2nd ed. Thousand Oaks, CA: Sage Publications, Inc; 2011.

35. Creswell JW, Klassen AC, Plano Clark VL, et al. Best practices for mixed methods research in the health sciences. Office of Behavioral and Social Sciences Research (OBSSR); 2011.

36. Nay B, Knivila K. Oregon's Coordinated Care Organizations-Health system transformation or managed care revisited? Insights. Williamette Management Associates; 2013.

37. OregonLaws.org. 2015 ORS 414.627 Community Advisory Councils. 2015.

38. McConnell K. Oregon's Medicaid coordinated care organizations. JAMA 2016;315:869-70.

39. McConnell KJ, Renfro S, Chan BK, et al. Early performance in Medicaid accountable care organizations: A comparison of Oregon and Colorado. JAMA Intern Med 2017;177(4):538-545.

40. Oregon Health Authority. CCO Metrics. 2013.

41. Oregon Health Authority. Oregon's health system transformation: CCO metrics 2015 final report. 2016.

42. Columbia Gorge Regional Community Health Assessment [PDF]. December 2013.

43. Worthley DL, Cole SR, Mehaffey S, et al. Participant satisfaction with fecal occult blood test screening for colorectal cancer. J Gastroenterol Hepatol 2007;22:142-3.

44. Deutekom M, van Rossum LG, van Rijn AF, et al. Comparison of guaiac and immunological fecal occult blood tests in colorectal cancer screening: The patient perspective. Scand J Gastroenterol 2010;45: 1345-9.

45. Neergaard MA, Olesen F, Andersen RS, et al. Qualitative description-The poor cousin of health research? BMC Med Res Methodol 2009;9(1):52.

46. Sandelowski $M$. Whatever happened to qualitative description? Res Nurs Health 2000;23:334-40.

47. File Update Summary: Colorectal Cancer: Screening. July 2015. Available from: https://www. uspreventiveservicestaskforce.org/Page/Document/ UpdateSummaryFinal/colorectal-cancer-screening.

48. Cole SR, Young GP, Esterman A, et al. A randomised trial of the impact of new faecal haemoglobin test technologies on population participation in screening for colorectal cancer. J Med Screen 2003; 10:117-22.

49. Gordon NP, Green BB. Factors associated with use and non-use of the fecal immunochemical test (fit) kit for colorectal cancer screening in response to a 2012 outreach screening program: A survey study. BMC Pub Health 2015;15(1):546.

50. O'Sullivan I, Orbell S. Self-sampling in screening to reduce mortality from colorectal cancer: A qualitative exploration of the decision to complete a faecal occult blood test (FOBT). J Med Screen 2004;11: $16-22$.

51. Coronado GD, Sanchez J, Petrik A, et al. Advantages of wordless instructions on how to complete a fecal immunochemical test: Lessons from patient advisory council members of a federally qualified health center. Journal Cancer Educ 2014;29:86-90.

52. Chiang TH, Lee YC, Tu CH, et al. Performance of the immunochemical fecal occult blood test in predicting lesions in the lower gastrointestinal tract. CMAJ 2011;183:1474-81.

53. Cheng TI, Wong JM, Hong CF, et al. Colorectal cancer screening in asymptomaic adults: Comparison of colonoscopy, sigmoidoscopy and fecal occult blood tests. J Formos Med Assoc 2002;101:685-90.

54. Benefits. The new recommended technology for occult blood detection to aid in colorectal cancer screening. Available from: http://hemosure.com/ sales/benefits/. Accessed March 23, 2017.

55. Smith A, Young GP, Cole SR, et al. Comparison of a brush-sampling fecal immunochemical test for hemoglobin with a sensitive guaiac-based fecal occult blood test in detection of colorectal neoplasia. Cancer 2006;107:2152-9.

56. Allison JE, Sakoda LC, Levin TR, et al. Screening for colorectal neoplasms with new fecal occult blood tests: Update on performance characteristics. J Natl Cancer Inst 2007;99:1462-70.

57. Ko CW, Dominitz JA, Nguyen TD. Fecal occult blood testing in a general medical clinic: Comparison between guaiac-based and immunochemicalbased tests. Am J Med 2003;115:111-4. 
Appendix 1. Images and Materials Associated with Each FIT Kit Tested ( $\mathrm{N}=6$ FITs)

\section{OC-Light ${ }^{\circledR}$}

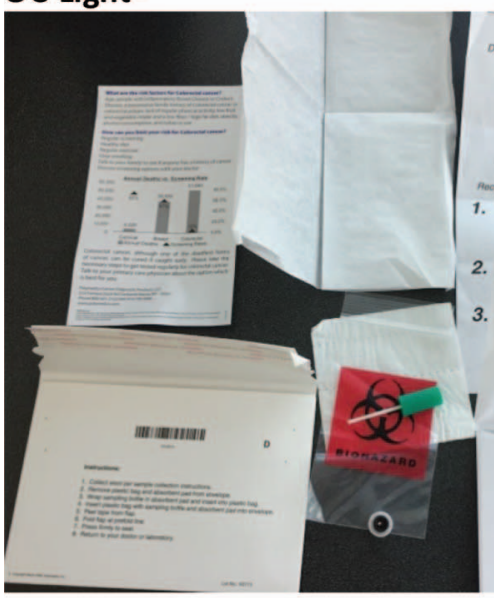

Hemosure $^{\circledR}$ iFOB Test

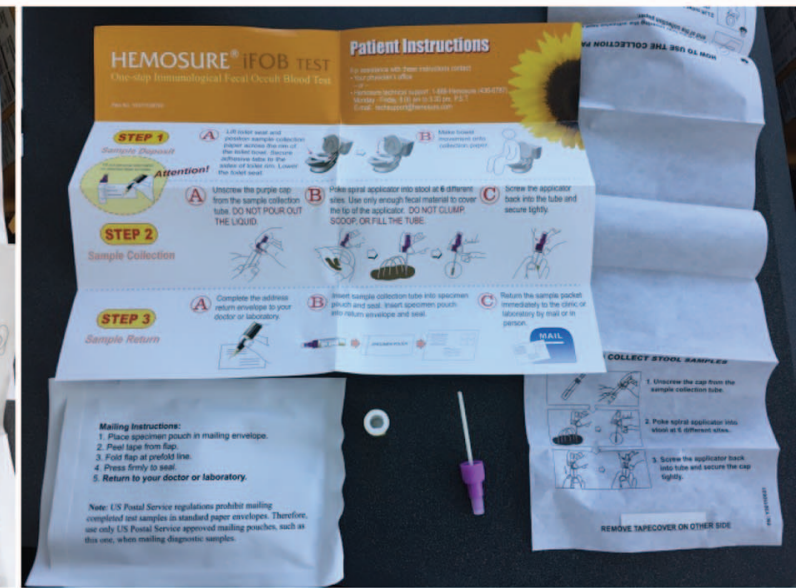

InSure ${ }^{\circledR}$

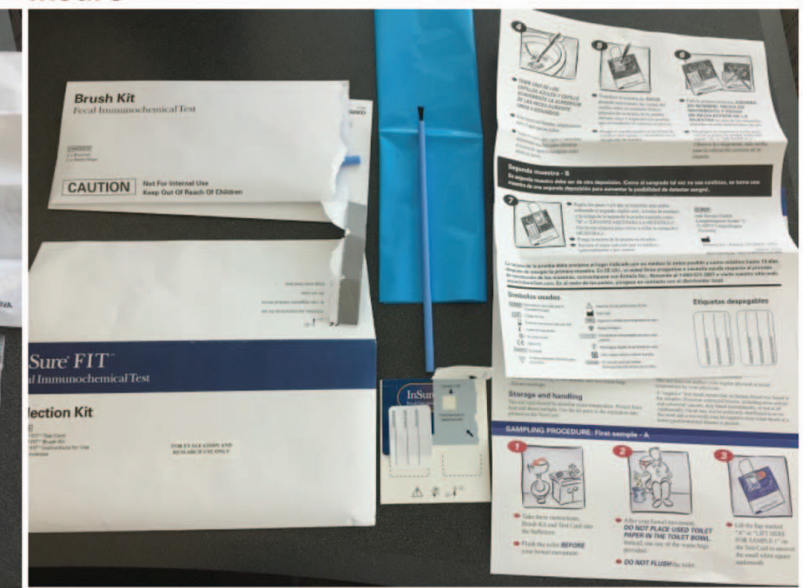

\section{OneStep+}

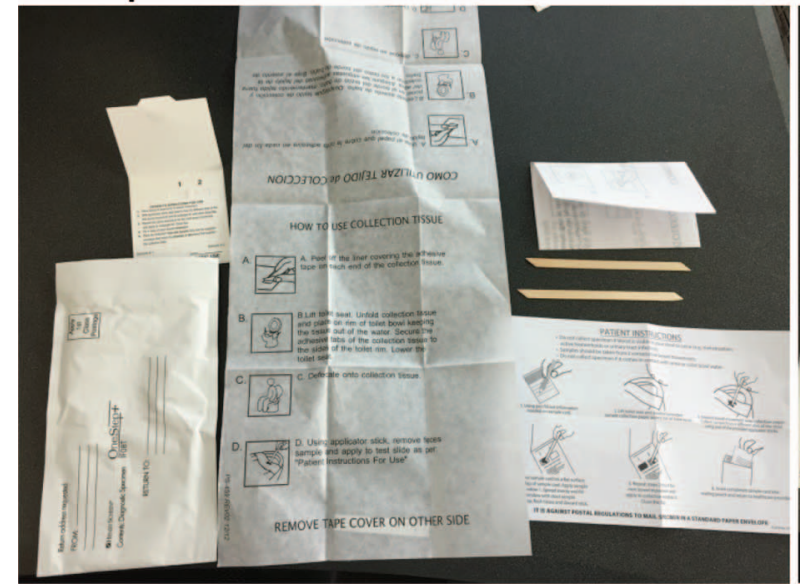

Hemoccult $^{\circledR}$

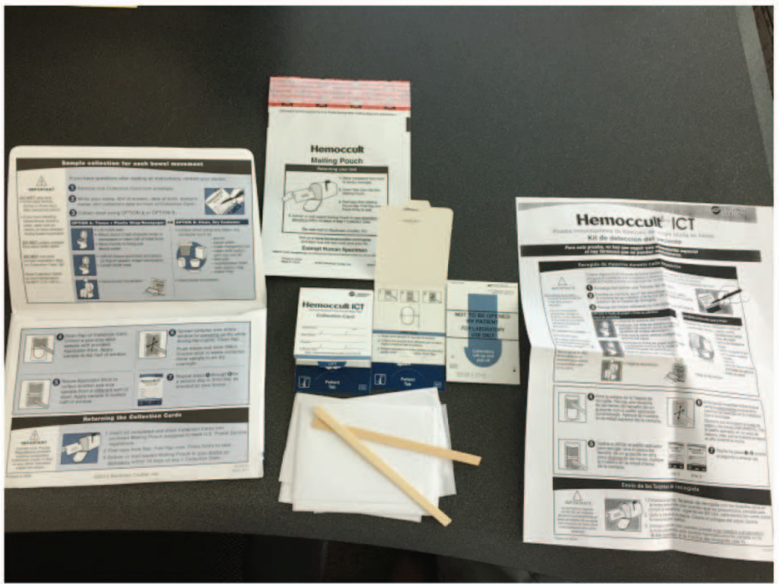


Please complete one form for each FIT kit as soon as you are done with that kit.

Return this completed form and completed FIT kit by mail using the envelope provided within 2 weeks.

Participant \#

Brand name of KIT you are rating:

\begin{tabular}{|c|c|c|c|c|}
\hline & $\begin{array}{l}\text { Strongly } \\
\text { Disagree }\end{array}$ & Disagree & Agree & $\begin{array}{r}\text { Strongly } \\
\text { agree }\end{array}$ \\
\hline 1. The kit package was easy to open. & $\square$ & $\square$ & $\square$ & $\square$ \\
\hline 2.The directions were confusing. & $\square$ & $\square$ & $\square$ & $\square$ \\
\hline $\begin{array}{l}\text { 3. After reading the directions, I felt sure I knew } \\
\text { how to use the kit correctly. }\end{array}$ & $\square$ & $\square$ & $\square$ & $\square$ \\
\hline
\end{tabular}

\begin{tabular}{|l|c|c|c|c|}
\hline & $\begin{array}{c}\text { Strongly } \\
\text { Disagree }\end{array}$ & Disagree & Agree & $\begin{array}{c}\text { Strongly } \\
\text { agree }\end{array}$ \\
\hline $\begin{array}{l}\text { 4.I had problems collecting the stool sample. } \\
\text { 5.The collection tool (tube, brush or stick) } \\
\text { was easy for me to use. }\end{array}$ & $\square$ & $\square$ & $\square$ & $\square$ \\
\hline 6.Collecting the sample was quick. & $\square$ & $\square$ & $\square$ & $\square$ \\
\hline 7.Collecting the sample was disgusting. & $\square$ & $\square$ & $\square$ & $\square$ \\
\hline 8.I feel confident I did everything correctly. & $\square$ & $\square$ & $\square$ & $\square$ \\
\hline
\end{tabular}

\begin{tabular}{|c|c|c|c|c|}
\hline & $\begin{array}{l}\text { Strongly } \\
\text { Disagree }\end{array}$ & Disagree & Agree & $\begin{array}{r}\text { Strongly } \\
\text { agree }\end{array}$ \\
\hline 1.1 know how to return the kit. & $\square$ & $\square$ & $\square$ & $\square$ \\
\hline 2.I have a convenient place to mail the kit. & $\square$ & $\square$ & $\square$ & $\square$ \\
\hline $\begin{array}{l}\text { 3. Most people I know would be willing to } \\
\text { complete a kit like this. }\end{array}$ & $\square$ & $\square$ & $\square$ & $\square$ \\
\hline 4.Using this kit was no big deal. & $\square$ & $\square$ & $\square$ & $\square$ \\
\hline
\end{tabular}


13. How many different bowel movements were required to complete this kit? $\begin{array}{llll}1 & 2 & 3\end{array}$ If more than 1 bowel movement was required, please answer the following:

\begin{tabular}{|c|c|c|c|c|}
\hline & $\begin{array}{l}\text { Strongly } \\
\text { Disagree }\end{array}$ & Disagree & Agree & $\begin{array}{c}\text { Strongly } \\
\text { agree }\end{array}$ \\
\hline $\begin{array}{l}\text { 13a. It was embarrassing to store the stool card } \\
\text { between samples. }\end{array}$ & $\square$ & $\square$ & $\square$ & $\square$ \\
\hline $\begin{array}{l}\text { 13b. I would rather do a one-sample test, even if } \\
\text { a multi-day test is a little better at finding } \\
\text { symptoms of cancer. }\end{array}$ & $\square$ & $\square$ & $\square$ & $\square$ \\
\hline $\begin{array}{l}\text { 13c. I would rather do a one-sample test, even if } \\
\text { a multi-day test is a lot better at finding } \\
\text { symptoms of cancer. }\end{array}$ & $\square$ & $\square$ & $\square$ & $\square$ \\
\hline
\end{tabular}

14. How many days did it take you to do all of the steps for this FIT kit, from receiving the package to getting the completed kit ready to mail? Circle your answer.

\section{$\begin{array}{lllllllllllllll}1 & 2 & 3 & 4 & 5 & 6 & 7 & 8 & 9 & 10 & 11 & 12 & 13 & 14 & 15+\end{array}$}

15. Overall, what did you think about completing this FIT kit? If you have completed the other kits as part of this study, is this kit better or worse?

16. What problems, if any, did you have using this kit?

17. Please share any additional comments or thoughts here. 


\section{Appendix 3. FIT Kit Evaluation Rubric Used in Specimen Adequacy Analysis}

Participant \#:

Test Kit \#:

1) "Packaged correctly" (if applicable):

a) For all tests - Was the specimen returned inside the mailer (without regard to whether it was sealed or left unsealed)?

b) For vial tests - Was the specimen inside the biohazard bag/inner envelope (without regard to whether it was sealed)?

c) For vial tests - Was the absorbent pad in the bag/envelope?

2) "Labeled correctly"

a) Was the specimen labeled in any way?

b) For card-based tests-Are the stool specimens dated on different days?

c) For all tests-Is the collection date listed?

3) "Sampled correctly"

For vial tests

a) Liquid appearance

For card-based tests

a) Number of cards returned

b) Do the specimens appear different from each other in color or texture?

c) Specimen appearance

d) Percentage of test area with visible staining or solid stool

e) Were the specimen cards closed according to instructions (without regard to whether the adhesive seal was used)?

$\mathrm{Y}^{*} / \mathrm{N}$
$\mathrm{Y} / \mathrm{N}$
$\mathrm{Y} / \mathrm{N}$
$\mathrm{Yes}$ Correctly/Yes, but incorrectly/No
$\mathrm{Y}^{*} / \mathrm{N}$
$\mathrm{Y} / \mathrm{N}$
$\mathrm{Y} / \mathrm{N}$
$\mathrm{Y} / \mathrm{N}$
$\mathrm{Y}^{*} / \mathrm{N}$

Clear/Tan/Brown

$1 / 2 / 3$

$\mathrm{Y} / \mathrm{N}$

None / Staining / Solid

$0 / 1 \%$ to $50 \% / 51 \%$ to $80 \% / 80 \%$ to $100 \%$ $\mathrm{Y} / \mathrm{N}$

${ }^{*}$ Where $\mathrm{Y}=$ yes to all. 


\title{
Appendix 4. Semi-structured Interview Guide for Focus Groups
}

\author{
Materials to bring: \\ Study Information sheet \\ Gift cards of appreciation \\ Food \\ Information handouts from American Cancer Society in English and Spanish \\ FIT kits \\ Recorder \\ Flip chart and markers \\ Prior to Starting Focus Group \\ Hand out study information sheet and review with participants \\ Welcome Group \\ Introductions \\ Thanks for coming \\ Purpose of today's meeting
}

Help us better understand opinions on the FIT kits that are used in the community and understand the best ways to educate about CRC prevention

- Gather valuable opinions from the group about the FIT kits

○ How to educate the community on CRC screening

Ground rules to encourage participation and ensure everyone feels safe sharing their thoughts

$\circ$ As the information sheet indicated, the information you provide will be kept private and so will the identity of every person participating in this study.

$\circ$ It's best if only one person speaks at a time. It is important that we all listen and try to understand what each other is saying.

○ If someone says something and I say "do you all agree with that statement?" No comment assumes you agree.

$\circ$ As you answer questions, I may ask you follow-up questions to help make sure I understand your responses.

○ There are no "right" or "wrong" answers.

O It is important for you to know that you do not have to answer any questions if you do not want to.

Any questions?

Announce you are turning on recorder [turn on audio recorder].

[Note: These questions provide a semi-structured guide for the discussion. Follow-up questions may be necessary for further clarification.] Questions for the group:

1) I know we know many of you, but can we quickly go around the room and have you state your name.

FIT test questions: Let's talk about the FIT kits (group facilitator to take out all the FIT kits and have them in front of the group)

2) Brainstorm overall impressions of the process of FIT testing and the kits

3) Discuss each FIT kit and if it was one that you tried, please let us know what you liked about the kit and what was challenging for you. Think about the tools given in the kit, the process, and directions.

4) Review Positives and Drawbacks for kits (materials, process, and directions).

5) Ask participants to agree on a ranking for all 6 kits from most preferred to least preferred.

6) Ask participants to make recommendations to the medical community about the FIT kits and FIT testing in general.

CRC Screening Questions:

7) Ask about CRC Screening (general brainstorm-what comes to mind?)

8) Ask: What makes it harder to complete screening? What are the barriers to screening?

9) Ask: What are some positives about testing? Can the group come up with ideas or ways to make screening a more positive experience?

Sharing Information about CRC screening:

10) Ask: Where do people get health information/CRC screening information from?

11) Ask: Who would they like to receive their health information from?

12) Ask: How do we increase education and awareness about CRC and screening in the community?

If time allows: ask for feedback on what went well and what could be improved on with this focus group.

Thank the group for coming and hand out resource materials. Read below:

We want to thank each and every one of you for participating in this project. We have realized that this effort was only one small piece in a long path toward improving linkages between primary care and community-based resources for CRC screening and awareness. Work in this area will continue to grow and your opinions and time are so valuable to us. We've learned a lot from this process and we greatly appreciate your time and energy in working on such an important area of research. 